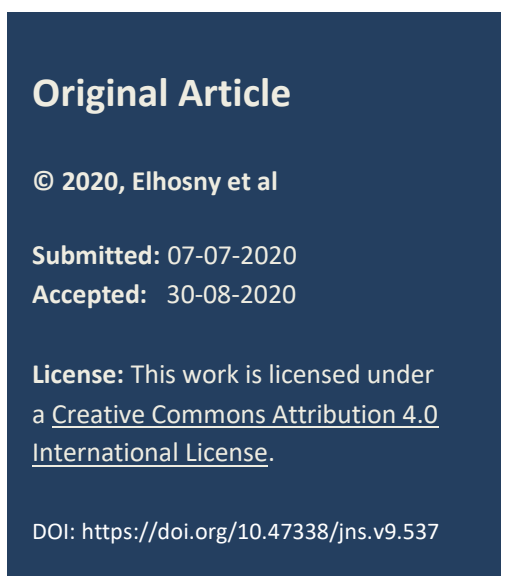

\section{Necrotizing enterocolitis in term neonates: Possible risk factors}

Ayman Elhosny, ${ }^{*}$ Corné de Vos, Behrouz Banieghbal

Paediatric Surgery Department at Tygerberg Children's Hospital, Faculty of Medicine and Health Sciences, Stellenbosch University, Cape Town, South Africa

Correspondence*: Dr. Ayman Elhosny, Paediatric Surgery Department at Tygerberg Children's Hospital, Faculty of Medicine and Health Sciences, Stellenbosch University, Cape Town, South Africa

E-mail: ayman.elhosny@gmail.com

\author{
KEYWORDS \\ Necrotizing enterocolitis, \\ NEC, \\ Term, \\ Neonates, \\ Risk factors, \\ Methamphetamine
}

\begin{abstract}
Background: Necrotizing enterocolitis (NEC) is a common surgical disease in premature neonates, however, it may occasionally occur in term neonates. The etiology of NEC in prematurity is multifactorial but is still not well understood in term neonates. In this study, the maternal and neonatal risk factors, along with underlying pathology that may precipitate NEC in term neonates are investigated.
\end{abstract}

Methods: A retrospective study investigating the maternal and neonatal risk factors for NEC in term neonates (G.A $\geq 37$ weeks) was performed over an 8-years period (January 2009 to March 2017). We used the second group of healthy term neonates over the same period as a control group. The data were collected from medical records. Term babies with the primary diagnosis of NEC were included in the review. Premature neonates (G.A <37 weeks) and NEC secondary to intestinal obstruction (e.g. Hirschsprung's disease) were excluded from the study.

Results: Of 194 babies with NEC, 14 were term neonates. Maternal risk factors: maternal age, Rhesus status, nicotine use, medication use, chronic and gestational illness were not found to be significant, however, maternal methamphetamine (MA) abuse was found to be a significant risk factor. Neonatal risk factors: genetic disorder, mode of delivery, type of milk, and invasive procedure were not found to be significant, but the presence of congenital heart disease (CHD) was a significant risk factor. Three neonates with CHD (3/4) in the group of term neonates with NEC also had maternal MA use.

Conclusion: NEC in term neonates is rarely encountered. CHD is well known to precipitate the disease in premature or full-term neonates, as also noted in this cohort. MA usage was also noted as a possible underlying cause.

\section{INTRODUCTION}

Necrotizing enterocolitis (NEC) is the most common neonatal surgical emergency affecting the bowel.[1] It predominantly affects preterm neonates and is a leading cause of morbidity and mortality in premature babies.[1,2] Although NEC is primarily a disease of prematurity, term neonates (Gestational age $\geq 37$ weeks) account for approximately $10 \%$ of NEC cases.[3]

NEC in premature neonates has a multifactorial etiology. NEC as a disease process in both premature and term neonates is similar clinically, radiologically, and histologically. The underlying risk factors as well as the pathophysiology of NEC in term neonates are not well understood. Term neonates acquiring NEC secondary to intestinal obstruction (e.g. Hirschsprung's Disease), is a well-known underlying pathology resulting from anaerobic bacterial colonization in the bowel [3-5]; however, NEC that may appear shortly after birth with congenital heart disease (CHD) represents the only definitive causative factor in this sub-group. [6-9]

Another possibility is that maternal factors may be one of the precipitating factors for NEC in term neonates. It is accepted that recreational drugs have adverse effects on the development of the fetus, but no obvious maternal factors have been reported as a risk factor for premature babies who develop NEC. The aim of this retrospective study was to identify 
possible risk factors for the development of NEC in term neonates.

\section{METHODS}

The study was conducted over an 8-year period (January 2009 - March 2017). Maternal and neonatal risk factors that may precipitate NEC in term neonates (G.A >37weeks) were investigated. Medical records were used to collect data for all the neonates with a primary diagnosis of NEC based on the Modified Bell's Criteria to confirm the diagnosis.

Premature neonates (GA <37 weeks) and term babies with NEC that developed secondary to neonatal intestinal obstruction (e.g. Hirschsprung's disease) were excluded.

A second group of neonates admitted over the same period, who did not develop NEC, were selected as a control group. This group consisted of term neonates with a prolonged hospital stay due to lack of transportation or social reasons.

The following maternal factors were noted: maternal age, Rhesus blood status, maternal blood transfusion, chronic or gestational illnesses, medication taken during and prior to the pregnancy, recreational drug usage, and mode of fetal delivery. Neonatal information that was documented included: gestational age, birth weight, antenatal intervention or any procedure, gender, associated congenital anomalies, invasive procedures done including blood transfusion postnatally, prescription medication, and presence of suspected sepsis.

Fisher exact and Student t-Test were used for statistical analysis and a p-value $<0.05$ was considered significant. Institutional Review Board (IRB) approval was also taken (\#0005239).

\section{RESULTS}

A total of 194 patients with Bell's Stage II - III NEC were treated at our institution. Fourteen of them were term neonates, 8 with Bell's stage IIb and 6 with Bell's stage III NEC. Eight were males and 6 were females. The median gestational age of the study group was 38.5 weeks ( 37 - 41 weeks) and the median age at presentation was 4.1 days ( 2 - 6.5 days). In contrast, 30 healthy neonates were included as a control group with a median GA of 38.6 weeks ( $37-41$ weeks) and an average hospital stay of 8 days. None of the babies in the study group received blood transfusions prior to the diagnosis. The median maternal age for term neonates with NEC was 29.6 years (range 15- 41 years) compared to 28.6 years (range 16- 45 years) in the comparison group ( $\mathrm{p}$-value $>0.2$ ).

Table 1: Maternal Risk factors

\begin{tabular}{|c|c|c|c|c|}
\hline Maternal Risk factors & & NEC Group (14) & $\begin{array}{c}\text { Comparison Group } \\
(\mathbf{3 0})\end{array}$ & p-value \\
\hline \multicolumn{5}{|l|}{ Medical Condition } \\
\hline & Hypertension & 2 & 9 & $\mathrm{~N} / \mathrm{S}$ * \\
\hline & Preeclampsia & 2 & 11 & $\mathrm{~N} / \mathrm{S}$ \\
\hline & Diabetes Mellitus (DM) & 0 & 3 & $\mathrm{~N} / \mathrm{S}$ \\
\hline & Gestational DM & 3 & 4 & $\mathrm{~N} / \mathrm{S}$ \\
\hline & Hypothyroidism & 0 & 1 & $\mathrm{~N} / \mathrm{S}$ \\
\hline & Schizophrenia & 0 & 1 & $\mathrm{~N} / \mathrm{S}$ \\
\hline & Human immunodeficiency virus & 1 & 0 & $\mathrm{~N} / \mathrm{S}$ \\
\hline & Tuberculosis & 0 & 0 & $\mathrm{~N} / \mathrm{S}$ \\
\hline \multicolumn{5}{|l|}{$\begin{array}{l}\text { Drugs used during } \\
\text { pregnancy }\end{array}$} \\
\hline & Methamphetamine & 4 & $\mathbf{0}$ & $<0.01$ \\
\hline & Olanzapine & 0 & 1 & $\mathrm{~N} / \mathrm{S}$ \\
\hline & Metformin & 1 & 3 & $\mathrm{~N} / \mathrm{S}$ \\
\hline & Folic acid & 1 & 3 & $\mathrm{~N} / \mathrm{S}$ \\
\hline & Iron supplement & 1 & 7 & $\mathrm{~N} / \mathrm{S}$ \\
\hline & Methyldopa & 2 & 5 & $\mathrm{~N} / \mathrm{S}$ \\
\hline & Insulin & 1 & 0 & $\mathrm{~N} / \mathrm{S}$ \\
\hline & Tobacco & 1 & 6 & $\mathrm{~N} / \mathrm{S}$ \\
\hline
\end{tabular}

\footnotetext{
* Non-significant
} 
Maternal risk factors identified are tabulated in Table 1. Maternal age, Rhesus blood status, nicotine usage, infection, acute/chronic medication use, gestationalrelated illness, and blood transfusion in the mother did not differ significantly between 2 groups.

Maternal Methamphetamine (MA) use during the pregnancy period was noted in four cases $(4 / 14)$ in term neonates with NEC, in comparison, none $(0 / 30)$ were found in the healthy neonates. The differences between the 2 groups were significant (Fisher's exact test, p-value < 0.01). The precise amount and frequency of MA usage were not disclosed.

Neonatal risk factors identified are tabulated (Table 2). Dysmorphic features, birth weight, gestational age, sepsis, breast/formula feeds, and whether the neonate underwent any invasive procedures (e.g. central venous line insertion and umbilical vessel catheter) showed no significant difference between the 2 groups.

Congenital heart disease (CHD) was recorded in eight cases (5 PDA, 2 complex cardiac anomalies, 1 peripheral pulmonary stenosis) of the term neonates with NEC and none (0/30) were present in the healthy neonates. This difference is significant $(\mathrm{p}<$ 0.01). None of these cases received surgical intervention for the cardiac lesions during this period however the exact nature of medical intervention was uncertain in terms of hemodynamic status. Three of the CHD (3/4) neonates with NEC also had maternal MA use. This was not noted in the comparison group. This difference is significant $(p<0.01)$.

Table 2: Neonatal Risk factors

\begin{tabular}{|c|c|c|c|c|}
\hline Neonatal Risk factors & & NEC Group (14) & $\begin{array}{c}\text { Comparison Group } \\
(30)\end{array}$ & p-value \\
\hline \multicolumn{5}{|l|}{ Weight } \\
\hline & Weight $1.8-3.4 \mathrm{~kg}$ & 10 & 23 & $\mathrm{~N} / \mathrm{S}$ \\
\hline & Weight $3.5-4.5 \mathrm{~kg}$ & 4 & 7 & $\mathrm{~N} / \mathrm{S}$ \\
\hline \multicolumn{5}{|l|}{ Interventions } \\
\hline & Intubation & 1 & 0 & $\mathrm{~N} / \mathrm{S}$ \\
\hline & Umbilical vessel catheter & 1 & 0 & $\mathrm{~N} / \mathrm{S}$ \\
\hline & Contrast meal study & 1 & 0 & $\mathrm{~N} / \mathrm{S}$ \\
\hline \multicolumn{5}{|l|}{ Neonatal co-morbidities } \\
\hline & Neonatal Jaundice & 0 & 1 & $\mathrm{~N} / \mathrm{S}$ \\
\hline & Congenital heart disease & 8 & $\mathbf{0}$ & $<0.01$ \\
\hline & Congenital pneumonia & 1 & 0 & $\mathrm{~N} / \mathrm{S}$ \\
\hline & Trisomy 21 & 1 & 0 & $\mathrm{~N} / \mathrm{S}$ \\
\hline & Di-George syndrome & 1 & 0 & $\mathrm{~N} / \mathrm{S}$ \\
\hline & E-Coli sepsis & 1 & 0 & $\mathrm{~N} / \mathrm{S}$ \\
\hline \multicolumn{5}{|l|}{ Feed } \\
\hline & Breast & 9 & 28 & $\mathrm{~N} / \mathrm{S}$ \\
\hline & Formula & 3 & 2 & $\mathrm{~N} / \mathrm{S}$ \\
\hline
\end{tabular}

NB. 2 Patients in the NEC group were nil per mouth.

\section{DISCUSSION}

In this study, we noted two significant risk factors (maternal MA use and neonatal CHD) that were significant in term NEC cases. MA is a common addictive drug in South Africa, Canada, the United States, and Southeast Asia. Police reports estimate the costs of between 1-1.5 US\$ per usage compared to cocaine or heroin, which costs between 6-14 US\$. [10-12] MA's cheap price has resulted in widespread abuse when compared to other illegal addictive drugs. [13] MA is an indirect sympathomimetic agent, which increases monoamine neurotransmission resulting in wakefulness, a boost in energy, as well as the excess sympathetic tone that mediates many of its adverse health effects. [13]

But, MA also causes tachycardia, hypertension, arterial vasoconstriction, bronchodilator, hyperglycemia, increased mental alertness, and decrease the fatigability and the same time has an adverse effect on the Central nervous system, cardiovascular system, gastrointestinal system, and immunity.[13] MA abuse is associated with necrotizing angiitis this may 
be due to the release of dopamine and noradrenaline that cause arterial vasoconstriction, which leads to tissue ischemia and necrosis.[14,15] MA also inhibits the immune system by reducing the number and function of macrophages, natural killer cells, monocytes, and granulocytes, contributing to the increased susceptibility to infections. [14]

There has been a multitude of studies done regarding the mechanism of action of MA and how it affects human adults, but limited studies are available about the effect of MA on the fetus. Antenatal exposures to MA during pregnancy in maternal abuse cases were shown in a hair follicle study, which showed transplacental transfer of the drug. This data indicated that positive exposure to MA might have adverse implications for fetal safety. A positive hair test for MA in the fetus was reported as a biomarker of maternal addiction by the seventh month of pregnancy. [16] It was also shown that the fetus is exposed to a similar dosage of the drug to the mother and may therefore have similar complications.

Maternal MA use has a possible teratogenic influence in the cardiac development of the fetus during the pregnancy and causes CHD. [17] In this situation it will be difficult to know the underlying cause of NEC, it's either the direct effect of MA on the fetus or MA cause CHD that may precipitate $\mathrm{NEC}$, this requires further investigation.

Presumably, NEC in term neonates occurs in case of maternal MA abuse because of sympathetic overstimulation this may result in arterial vasoconstrictor to the placenta or in fetal gut vessels and that can cause ischemia of the bowel or alternatively, MA can result in inhibition on the immunity, by reducing the number and function of immune cell. In addition impairment in the immune-gut mucosal barrier due to mucosal ischemia can cause bacterial translocation and increase the risk of NEC.

Congenital heart disease (CHD) was noted in our cohort of NEC in term neonates. It was the only neonatal factor identified in our study. Acyanotic congenital heart diseases were the commonest CHD in our study group, although cyanotic congenital heart disease (CCHD) has been reported to be associated with NEC development in infants of all gestational ages

\section{REFERENCES}

1. Gupta A, Paria A. Etiology and medical management of NEC. Early Hum Dev. 2016; 97:17-23.

2. Thakkar HS, Lakhoo $\mathrm{K}$. The surgical management of necrotising enterocolitis (NEC). Early Hum Dev. 2016; 97:25-8.

3. Raboel EH. Necrotizing enterocolitis in full-term neonates: Is it aganglionosis? Eur J Pediatr Surg. 2009; 19:101-4. and remain the commonest underlying anomaly associated with NEC. $[4,7,8]$

PDA with NEC was reported in neonates who were receiving indomethacin as a treatment. Theoretically, the vasoconstriction effect of indomethacin may cause impair of the mesenteric blood flow and could cause ischemia to the bowel. [1] None of the patients in our study group received any medical or cardiac interventions prior to NEC, so the pathophysiology for NEC here is unclear and may need to be further investigated.

This study has shown that both maternal MA use and CHD are significantly associated with NEC in term neonates at this institution. Given the discussed mechanism of action as well as the fact that MA use is associated with the development of $\mathrm{CHD}$, it seems possible that maternal MA use is directly linked to the development of NEC. The author suggests larger quantitative studies to further investigate this possible link. Small sample size, no information on frequency and dosage of recreational drug abuse, and undetermined combined role of $\mathrm{CHD}$ and MA abuse in term NEC development are the limitations of our study and future research should also work on these aspects of NEC in term neonates.

\section{CONCLUSION}

NEC in a term neonate is a rare event. Cardiac anomalies are well known to precipitate the disease in premature or full-term neonates, as noted in this cohort. MA usage is a possible underlying cause. MA abuse should alert pediatricians and pediatric surgeons to closely monitor full-term neonates with or without CHD for the development of NEC. Better yet, primary healthcare workers, obstetricians, and gynecologists at large ought to be made aware of the possible preventative role they may play in advising the expectant mothers on the life-threatening consequences that MA use poses to the neonate.

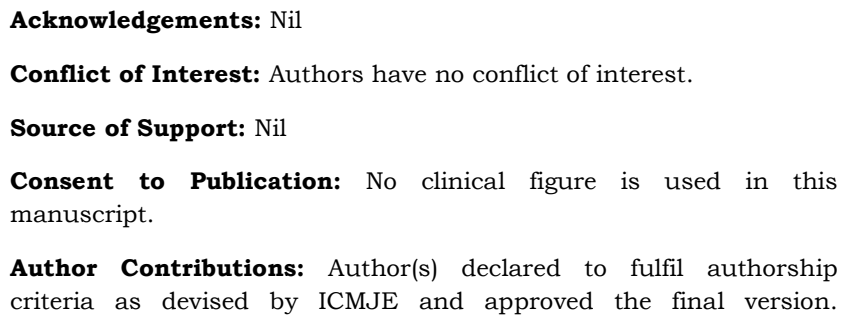

Author Contributions: Author(s) declared to fulfil authorship criteria as devised by ICMJE and approved the final version.

4. Overman RE, Criss CN, Gadepalli SK. Necrotizing enterocolitis in term neonates: A different disease process? J Pediatr Surg. 2019; 54:1143-6.

5. De La Cochetière MF, Piloquet $\mathrm{H}$, Des Robert C, Darmaun D, Galmiche JP, Rozé JC. Early intestinal bacterial colonization and necrotizing enterocolitis in premature infants: The putative role of Clostridium. Pediatr Res. 2004; 56:366-70. 
6. Maayan-Metzger A, Itzchak A, Mazkereth $\mathrm{R}$, Kuint J. Necrotizing enterocolitis in full-term infants: Case-control study and review of the literature. J Perinatol. 2004; 24:494-9.

7. Ostlie DJ, Spilde TL, St Peter SD, Sexton N, Miller KA, Sharp RJ, et al. Necrotizing enterocolitis in full-term infants. J Pediatr Surg. 2003; 38:1039-42.

8. Bolisetty S. A regional study of underlying congenital diseases in term neonates with necrotizing enterocolitis. Acta Paediatr. 2000; 89:1226-30.

9. McElhinney DB, Hedrick HL, Bush DM, Pereira GR, Stafford PW, Gaynor JW, et al. Necrotizing enterocolitis in neonates with congenital heart disease: Risk factors and outcomes. Pediatrics. 2000; 106):1080-7.

10. Tik - the only product costing you less [Internet]. [cited 2020 Jun 12]. Available from: https: / / www.iol.co.za/news/tik-the-only-productcosting-you-less-1927489

11. Community Intervention Centre | Trauma Psychology in Cape Town, Western Cape, South Africa [Internet]. [cited 2020 Jun 12]. Available from: http:/ / www.blaauwberg.net/cic/articles/drugs/cocaine. asp

12. Drug dealers are making as much as $\mathrm{R} 4,000$ a day from South Africa's growing heroin epidemic [Internet]. [cited
2020 Jun 12]. Available from: https://businesstech.co.za/news/lifestyle/310786/drug -dealers-are-making-as-much-as-r4000-a-day-fromsouth-africas-growing-heroin-epidemic/

13. Vearrier D, Greenberg MI, Miller SN, Okaneku JT, Haggerty DA. Methamphetamine: history, pathophysiology, adverse health effects, current trends, and hazards associated with the clandestine manufacture of methamphetamine. Disease-a-Month. 2012; 58:38-89.

14. Prakash MD, Tangalakis K, Antonipillai J, Stojanovska L, Nurgali K, Apostolopoulos V. Methamphetamine: Effects on the brain, gut and immune system. Vol. 120, Pharmacological Research. Academic Press; 2017. p. 607.

15. Attaran H. Fatal Small intestinal ischemia due to methamphetamine intoxication: Report of a case with autopsy results. Acta Med Iran. 2017; 55:344-7.

16. Garcia-Bournissen F, Rokach B, Karaskov T, Koren G Methamphetamine detection in maternal and neonatal hair: Implications for fetal safety. Arch Dis Child Fetal Neonatal Ed. 2007; 92.F351-5.

17. Nora J, Vargo T, Nora A, Love K, Mcnamara D. Dexamphetamine: a possible environmental trigger in cardiovascular malformations. The Lancet. 1970; 295:1290-1. 